\title{
Engineering a highly active thermophilic $\beta$-glucosidase to enhance its pH stability and saccharification performance
}

Wei Xia ${ }^{1,2+}$, Xinxin X $\mathrm{u}^{3 \dagger}$, Lichun Qian ${ }^{2}$, Pengjun Shi ${ }^{1 *}$, Yingguo Bai ${ }^{1}$, Huiying Luo ${ }^{1}$, Rui Ma ${ }^{1}$ and Bin Yao ${ }^{1 *}$

\begin{abstract}
Background: $\beta$-Glucosidase is an important member of the biomass-degrading enzyme system, and plays vital roles in enzymatic saccharification for biofuels production. Candidates with high activity and great stability over high temperature and varied $\mathrm{pHs}$ are always preferred in industrial practice. To achieve cost-effective biomass conversion, exploring natural enzymes, developing high level expression systems and engineering superior mutants are effective approaches commonly used.
\end{abstract}

Results: A newly identified $\beta$-glucosidase of GH3, Bgl3A, from Talaromyces leycettanus JCM12802, was overexpressed in yeast strain Pichia pastoris GS115, yielding a crude enzyme activity of $6000 \mathrm{U} / \mathrm{ml}$ in a $3 \mathrm{~L}$ fermentation tank. The purified enzyme exhibited outstanding enzymatic properties, including favorable temperature and $\mathrm{pH}$ optima $\left(75^{\circ} \mathrm{C}\right.$ and $\mathrm{pH}$ 4.5), good thermostability (maintaining stable at $60^{\circ} \mathrm{C}$ ), and high catalytic performance (with a specific activity and catalytic efficiency of $905 \mathrm{U} / \mathrm{mg}$ and $9096 / \mathrm{s} / \mathrm{mM}$ on $p N P G$, respectively). However, the narrow stability of Bgl3A at $\mathrm{pH}$ 4.0-5.0 would limit its industrial applications. Further site-directed mutagenesis indicated the role of excessive O-glycosylation in $\mathrm{pH}$ liability. By removing the potential O-glycosylation sites, two mutants showed improved pH stability over a broader $\mathrm{pH}$ range (3.0-10.0). Besides, with better stability under $\mathrm{pH} 5.0$ and $50^{\circ} \mathrm{C}$ compared with wild type Bgl3A, saccharification efficiency of mutant M1 was improved substantially cooperating with cellulase Celluclast 1.5L. And mutant M1 reached approximately equivalent saccharification performance to commercial $\beta$-glucosidase Novozyme 188 with identical $\beta$-glucosidase activity, suggesting its great prospect in biofuels production.

Conclusions: In this study, we overexpressed a novel $\beta$-glucosidase Bgl3A with high specific activity and high catalytic efficiency in P. pastoris. We further proved the negative effect of excessive O-glycosylation on the pH stability of Bgl3A, and enhanced the $\mathrm{pH}$ stability by reducing the O-glycosylation. And the enhanced mutants showed much better application prospect with substantially improved saccharification efficiency on cellulosic materials.

Keywords: $\beta$-Glucosidase, Talaromyce leycettanus, Saccharification, pH stability, O-glycosylation, Pichia pastoris

\section{Background}

As one of the most abundant renewable energy sources on Earth, plant biomass mainly consists of lignocellulose, which is a complicated heterogeneous complex made up of hemicellulose, lignin and cellulose [1]. For the closest

\footnotetext{
*Correspondence: shipengjun@caas.cn; binyao@caas.cn; yaobin@caas.cn 'Wei Xia and Xinxin Xu contributed equally to this paper

${ }^{1}$ Key Laboratory for Feed Biotechnology of the Ministry of Agriculture, Feed Research Institute, Chinese Academy of Agricultural Sciences, No. 12 Zhongguancun South Street, Beijing 100081, People's Republic of China Full list of author information is available at the end of the article
}

decades, developing efficient technologies to convert biomass materials into fuels has attracted focused attention of researchers $[2,3]$. Moreover, the biodegradation of cellulosic materials has been reported to have potential importance in kinds of industrial and agricultural applications [4-7]. Some glycoside hydrolases (GHs) are the most effective enzymes to depolymerize cellulose. As generally known, endo- $\beta$-glucanase (EC 3.2.1.4, EG) that catalyzes the breakdown of internal $\beta$-1,4-linkages at random position of the glucose polymers, cellobiohydrolase (EC 3.2.1.91, CBH I and CBH II) that cuts off cellobiose 
residues from the reducing or nonreducing ends, and $\beta$-glucosidase (EC 3.2.1.21) that hydrolyzes single units from the nonreducing end into glucose $[3,8]$. In detail, EGs catalyze the breakdown of internal $\beta-1$, 4-linkages at random position of the glucose polymer chain, while $\mathrm{CBHs}$ cut-off cellobiose residues from the ends $(\mathrm{CBH}$ $\mathrm{I}$ and $\mathrm{CBH}$ II cuts from the reducing and nonreducing ends, respectively). At the last step, generated cellobiose or cello-oligosaccharides are hydrolyzed into single units of glucose from the nonreducing end by $\beta$-glucosidases. And recent researches reveal that a class of enzymes now known as lytic polysaccharide monooxygenases (LPMOs) are also important for the decomposition of recalcitrant biological macromolecules such as plant cell wall and chitin polymers [9]. LPMOs cleave the chains at the surface of the crystalline polymer by oxidation of the polysaccharide chain to contribute to further enzymatic action and eventual degradation [10]. These enzymes were originally designated glycoside hydrolase family 61 and carbohydrate-binding module family 33, but are now classified as auxiliary activities 9 (formerly GH61), 10 (formerly CBM33) and 11 in the CAZy database [11].

Several cellulolytic GHs have been commercialized for industrial production of biofuels and chemicals [12-15]. For example, Celluclast 1.5L (Novo Nodisk A/S) from Trichoderma reesei ATCC 26921 and newly developed Cellic $^{\circledR}$ CTec2 and Cellic ${ }^{\circledR}$ CTec3 are the most widely used commercial cellulolytic preparation $[16,17]$. However, its low $\beta$-glucosidase activity makes supplementation of exogenous enzyme necessary for efficient biomass conversion $[18,19]$. Since $\beta$-glucosidase plays a vital role in cellulose hydrolysis by undertaking the ratelimiting final step of hydrolyzing cellobiose, which is an intermediate product of cellulose hydrolysis and also a strong inhibitor of cellulase activities, into glucose [20, 21 ], it's a common practice to supplement exogenous $\beta$-glucosidase to enhance the saccharification efficiency of cellulosic materials [22-24]. This challenge remains a major bottleneck in the bioconversion process, and recent research has, therefore, shown increased interest in the search for novel $\beta$-glucosidases. Based on the amino acid sequences, $\beta$-glucosidases have been classified into GH families 1, 3, 5, 9, 30 and 116. Although enzymes from different families and different organisms vary greatly in properties and functions, cost-effective production, high hydrolytic efficiency and great tolerance to unfavorable conditions are prerequisites of an industrial biocatalyst in various applications [25]. Of particular interest, $\beta$-glucosidases from thermophilic fungi are more favorable due to the high-temperature activity and good thermostability [26, 27]. Recent advances have been made in $\beta$-glucosidase engineering and production [28-30]; however, much work is yet to be addressed for the improvement of $\beta$-glucosidases for industrial applications.

Incompatibility between enzymatic properties and process conditions is a common issue for enzyme commercialization. Thus, to discover and modify enzymes with favorable properties is a research focus for efficient utilization of plant biomass [31, 32]. pH stability, as an essential enzymatic property, is closely related to the factors that affect protein structure, such as protein folding, interferential chemicals and posttranslational modifications (PTMs) [33]. PTMs occur on the amino acid side chains or termini by introducing new functional groups such as phosphate (phosphorylation), acetate (acylation), amide groups (amidation), methyl groups (methylation), or carbohydrate molecules (glycosylation) [34]. Many eukaryotic proteins also have attached to them in a process called glycosylation, which can promote protein folding and improve stability as well as serving regulatory functions. Glycosylation represents one major PTM of eukaryotic proteins, which occurs at asparagine of the consensus motif Asn-X-Thr/Ser (where X is any amino acid except Pro; $N$-glycosylation) or serine and threonine residues (O-glycosylation) [29]. In contrast to the absence of glycosylation in prokaryotic expression systems like Escherichia coli, glycosylation is common in eukaryotic host systems (i.e., Pichia pastoris) and play important roles in proper folding, transport, and stability of proteins [23, 34-38]. Yeast strains are widely used for recombinant protein production, during which both $O$ and $\mathrm{N}$-glycosylations occur preceding protein secretion and have obvious effects on enzyme properties [39-41]. $P$. pastoris is capable of adding both $O$ - and $N$-linked carbohydrate moieties to secreted proteins. In comparison with the intensive studies of $\mathrm{N}$-glycosylation effect on enzyme properties [42], less was done to reveal the mechanism of $O$-glycosylation [43, 44].

The purpose of this study is to explore and develop a novel $\beta$-glucosidase with capacity of accelerating the conversion efficiency of cellulosic materials into glucose. We produced the $\beta$-glucosidase (Bgl3A) from Talaromyces leycettanus JCM12802 in P. pastoris and found its advantages and disadvantages for industrial applications. By removing $\mathrm{O}$-glycosylation, we improved the $\mathrm{pH}$ stability of the enzyme and enhanced the saccharification efficiency of the enzyme combination with commercial cellulase.

\section{Results}

\section{Gene cloning and sequence analysis}

A gene fragment of $\sim 4.3 \mathrm{~kb}$ containing the full-length $\beta$-glucosidase-encoding sequence ( $b g l 3 A, 2214 \mathrm{bp}$ ) was obtained from the genome of T. leycettanus JCM12802 using TAIL-PCR. bgl3A encodes a GH3 polypeptide 
of 737 amino acid residues and a termination codon. Deduced Bgl3A has a putative signal peptide at the $\mathrm{N}$-terminus (residues 1-19) and a mature protein with the calculated molecular mass and $p \mathrm{I}$ value of $76.3 \mathrm{kDa}$ and 4.98 , respectively. Three potential $N$-glycosylation sites (Asn23, Asn207 and Asn278) and nine potential O-glycosylation sites (residues Ser313, Thr417, Thr418, Ser419, Thr 420, Thr421, Thr424, Thr425 and Ser429) were identified in deduced Bgl3A, indicating the possible abundant posttranslational modification of Bgl3A when expressed in eukaryotic system. Deduced Bgl3A exhibits the highest sequence identities of $83 \%$ with a putative GH from Neosartorya fischeri NRRL 181 and $82 \%$ with GH3 $\beta$-glucosidase from Aspergillus fumigatus var. RP-2014. Blast analysis against the PDB database indicates that Bgl3A shares a rather high identity of $73 \%$ with a structure-resolved counterpart $\beta$-glucosidase, Cel3A, from Hypocrea jecorina (PDB: 3ZYZ) [45].

\section{Expression and purification of recombinant $\beta$-glucosidase Bgl3A}

The cDNA fragment of $b g l 3 A$ without the signal peptidecoding sequence was successfully expressed in $P$. pastoris GS115 and E. coli BL21. The production level of crude Bgl3A in P. pastoris GS115 reached $6000 \mathrm{U} / \mathrm{ml}$ (approximate $6 \mathrm{~g} / \mathrm{L}$ protein) in a $3 \mathrm{l}$ fermentation tank after $132 \mathrm{~h}$ ' growth. The crude enzymes were then concentrated, desalted and purified. SDS-PAGE analyses indicated the purified Bgl3A expressed in P. pastoris spread over the gel with the apparent molecular masses of $76-100 \mathrm{kDa}$ (Fig. 1a, lane 1), which was significantly higher than the calculated value $(76.3 \mathrm{kDa})$. This significant molecular weight variance might be ascribed to the glycosylation occurred in $P$. pastoris during heterologous expression. In contrast, the purified recombinant Bgl3A produced in $E$. coli (E. coli-Bgl3A) migrated a single band of calculated value (Fig. 1a, lane 6), suggesting that no glycosylation occurred on E. coli-Bgl3A.

\section{Characterization of purified recombinant Bgl3A}

The enzymatic properties of purified recombinant Bgl3A produced in $P$. pastoris were determined using 4-nitrophenyl $\beta$-D-glucopyranoside ( $p$ NPG) as the substrate. Purified Bgl3A was active over a narrow acid $\mathrm{pH}$ range, exhibiting optimal activity at $\mathrm{pH} 4.5$ and retaining $>65 \%$ activity at $\mathrm{pH} 4.0-5.0$ (Fig. 2a). The enzyme had poor $\mathrm{pH}$ stability, only retaining $>70 \%$ initial activity after $1 \mathrm{~h}$ incubation at $\mathrm{pH} 4.0-5.0$ and $37^{\circ} \mathrm{C}$ (Fig. 2b). When assayed Bgl3A activity at $\mathrm{pH} 4.5$, it exhibited maximum activity at $75{ }^{\circ} \mathrm{C}$ and remained $65 \%$ activity even at $80{ }^{\circ} \mathrm{C}$ (Fig. 2c). And Bgl3A was highly stable at $60{ }^{\circ} \mathrm{C}$, retaining $>65 \%$ activity after $1 \mathrm{~h}$ incubation at $60{ }^{\circ} \mathrm{C}$ without substrate, but lost activity

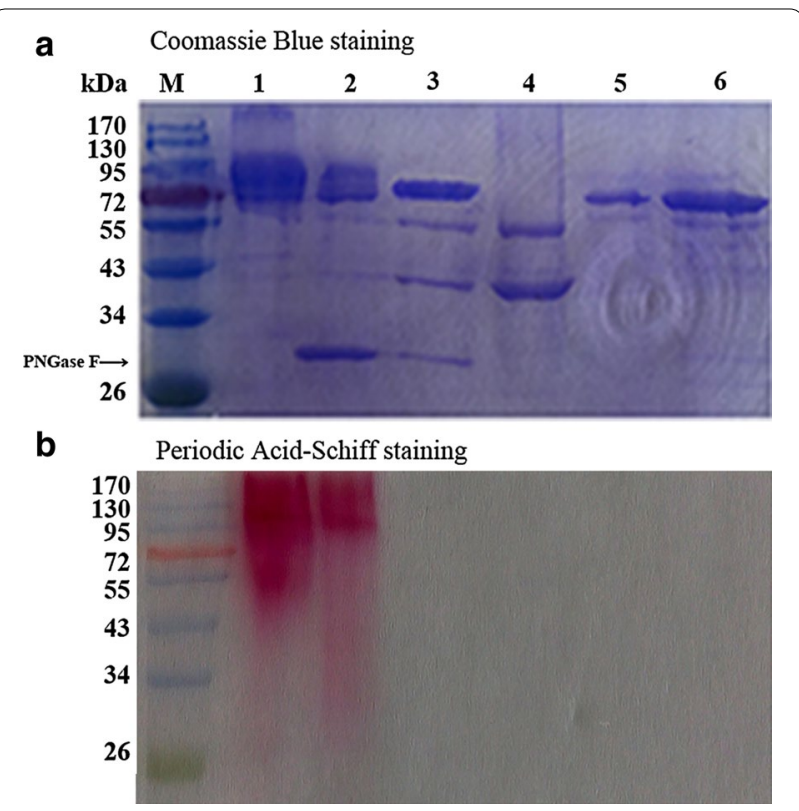

Fig. 1 SDS-PAGE analysis of the purified recombinant $\beta$-glucosidase Bgl3A with and without deglycosylation treatment. a Coomassie Blue staining. Lanes $\mathrm{M}$, the standard protein molecular weight markers; 1 the Bgl3A produced in P. pastoris; 2 the Bgl3A produced in P. pastoris and treated with PNGase $F ; 3$ the Bgl3A produced in $P$. pastoris and treated with PNGase $F$ followed by a-mannosidase; 4 the a-mannosidase; 5 the purified Bgl3A after sequential deglycosylation by PNGase F and a-mannosidase; 6 the Bgl3A produced in E. coli. b Periodic Acid-Schiff staining

rapidly when treated at 70 and $80{ }^{\circ} \mathrm{C}$ (Fig. 2d). However, E. coli-Bgl3A had similar properties as that produced in $P$. pastoris (data not shown), but exhibited stability over a much broader $\mathrm{pH}$ range from 4.0 to 11.0 (Fig. 3, dash line).

The effects of metal ions and chemical reagents on the activity of Bgl3A were determined at the concentrations of $5 \mathrm{mM}$ (Additional file 1). Bgl3A was highly resistant to most tested metal ions except for $\mathrm{Ag}^{+}$and $\mathrm{Cu}^{2+}$ and remained active in the presence of chemical reagents EDTA, $\beta$-mercaptoethanol, and SDS. Moreover, $\mathrm{Ca}^{2+}$ enhanced the Bgl3A activity by $20 \%$. Similar result was observed for CfGlu1C from Coptotermes formosanus [46]. $\mathrm{Ca}^{2+}$ even has stimulatory effects on the TpeBlg3 stability at high temperatures, and $5 \mathrm{mM}$ of $\mathrm{Ca}^{2+}$ enhances the activity by $58 \%$ [47].

\section{Substrate specificity and kinetic parameters}

The substrate specificities of purified recombinant Bgl3A are shown in Table 1 . It showed high specific activities of $905 \mathrm{U} / \mathrm{mg}$ on $p \mathrm{NPG}$ and $265 \mathrm{U} / \mathrm{mg}$ on cellobiose. When using disaccharides of different linkages as the substrate, the enzymes showed different levels of preference, in the order of gentiobiose $(\beta-1,6$ linkage $)>$ sophorose $(\beta-1,2$ 

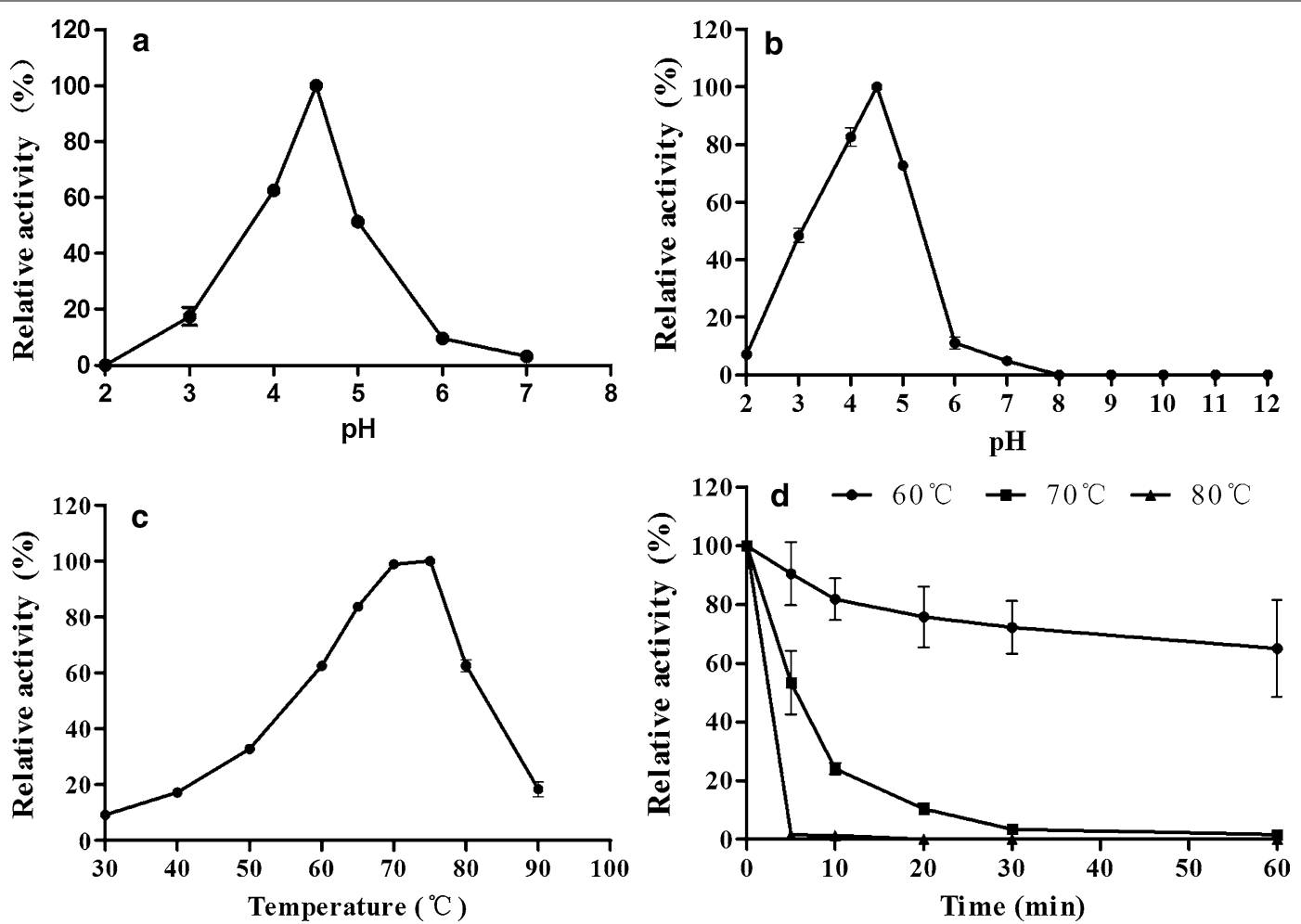

Fig. 2 Enzymatic properties of the purified recombinant Bgl3A produced in P. pastoris using $p N P G$ as the substrate. a Effect of pH on enzyme activities. $\mathbf{b}$ pH stability of Bgl3A after $1 \mathrm{~h}$ incubation at $37^{\circ} \mathrm{C}$. $\mathbf{c}$ Effect of temperature on enzyme activities. d Thermostability of Bgl3A at pH 4.5 and different temperatures up to $60 \mathrm{~min}$. Each value in the panel represents the mean $\pm \operatorname{SD}(n=3)$

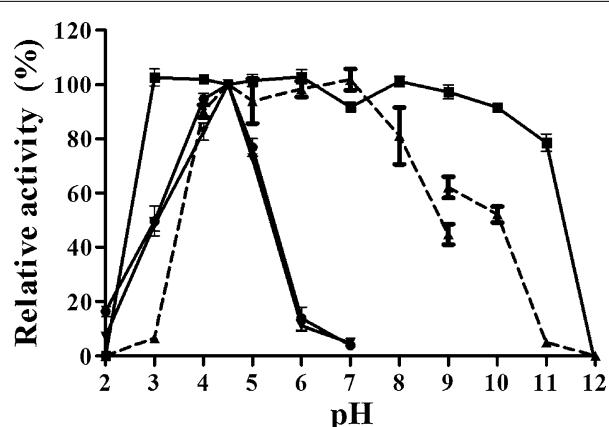

$$
\begin{aligned}
& \rightarrow \mathrm{Bgl} \mathrm{A} \\
& \rightarrow-\text { E.coli-Bgl3A } \\
& \rightarrow \quad N \text {-glycosylation Deglycosylated } \\
& \rightarrow O \text {-glycosylation Deglycosylated }
\end{aligned}
$$

Fig. 3 pH stabilities of glycosylated (produced in P. pastoris), nonglycosylated (produced in E. coli) and deglycosylated (treated with PNGase F and a-mannosidase) Bgl3A. The same amounts of enzymes were used for determination

linkage $)>$ cellobiose $(\beta-1,4$ linkage $)$. And for various arylglycoside substrates, Bgl3A was active with $p$ NPG and amygdalin as preferred substrates.
Table 1 Substrate specificity of purified recombinant $\beta$-glucosidase Bgl3A

\begin{tabular}{lc}
\hline Substrate & Specific activity $(\mathbf{U} / \mathbf{m g})^{\mathbf{a}}$ \\
\hline Disaccharides & \\
Gentiobiose $(\beta-1,6)$ & $393.2 \pm 0.1$ \\
Sophorose $(\beta-1,2)$ & $342.8 \pm 0.8$ \\
Cellobiose $(\beta-1,4)$ & $265.5 \pm 0.2$ \\
Aryl-glycosides & \\
$p$-Nitrophenyl $\beta$-D-glucopyranoside & $905.0 \pm 0.1$ \\
- -Nitrophenyl $\beta$-D-cellobioside & $76.6 \pm 0.0$ \\
Amygdalin & $377.4 \pm 0.2$ \\
Genistin & $175.3 \pm 0.3$ \\
Daidzin & $154.6 \pm 0.9$ \\
Glycitin & $75.6 \pm 0.6$
\end{tabular}

Data is shown as mean \pm standard deviation $(n=3)$

The kinetics of Bgl3A on substrates $p$ NPG and cellobiose are shown in Table 2. Bgl3A exhibited much higher substrate affinity $\left(K_{\mathrm{m}}, 57\right.$-folds) and catalytic efficiency $\left(k_{\text {cat }} / K_{\mathrm{m}}, 120\right.$-folds) on $p$ NPG than on cellobiose. The glucose inhibition constant $K_{\mathrm{i}}$ value of Bgl3A was determined to be $14 \mathrm{mM}$. 
Table 2 Kinetic parameters of $\beta$-glucosidase Bgl3A and its two mutants

\begin{tabular}{llllllll}
\hline Substrate & Enzyme & Specific activity $(\mathbf{U} / \mathbf{m g})$ & $\boldsymbol{K}_{\mathbf{i}}(\mathbf{m M})$ & $\boldsymbol{K}_{\mathbf{m}}(\mathbf{m M})$ & $\boldsymbol{V}_{\mathbf{m a x}}(\mathbf{U} / \mathbf{m g})$ & $\boldsymbol{k}_{\text {cat }}(/ \mathbf{s})$ & $\boldsymbol{k}_{\text {cat }} / \boldsymbol{K}_{\mathbf{m}}(\mathbf{s} / \mathbf{m M})$ \\
\hline pNPG & Bgl3A & 905 & 14.0 & 0.18 & 1309 & 1664 & 9096 \\
& M1 & 1019 & 17.0 & 0.31 & 1408 & 1791 & 5778 \\
\multirow{3}{*}{ Cellobiose } & M2 & 843 & 12.3 & 0.36 & 1679 & 2136 & 4664 \\
& Bgl3A & 265.5 & ND & 10.4 & 618.4 & 786.0 & 75.8 \\
& M1 & 209.4 & ND & 8.4 & 531.6 & 676.0 & 80.5 \\
& M2 & 197.6 & ND & 9.3 & 733.0 & 932.6 & 100.3 \\
\hline
\end{tabular}

ND not determined

\section{Deglycosylation and determination of pH stability of deglycosylated enzymes}

Results above, illustrated that Bgl3A is a highly active, thermophilic, acidic $\beta$-glucosidase, which is of much value for various industrial applications. The only defect is its poor $\mathrm{pH}$ stability. As we all know, prokaryotic expression systems differ hugely from eukaryotic systems in several aspects such as codon preference, secretion pathways and posttranslational modification. Among them, posttranslational modification influences most on the structure and property of the expressed protein. And $\mathrm{N}$-glycosylation and $\mathrm{O}$-glycosylation take over the largest part of posttranslational modification in yeast cells. The great $\mathrm{pH}$ stability difference between Bgl3A and E. coliBgl3A might be ascribed to glycosylation. Thus the $N$ and $\mathrm{O}$-glycans of Bgl3A were removed by PNGase $\mathrm{F}$ and $\alpha$-mannosidase sequentially, and determination of the $\mathrm{pH}$ stability of deglycosylated enzymes were done to verify whether or not glycosylation affected the $\mathrm{pH}$ tolerance of Bgl3A expressed in P. pastoris. The changes of molecular weight after deglycosylation were determined by SDSPAGE (Fig. 1a). According to the result, $N$-deglycosylated Bgl3A showed lower coomassie brilliant blue staining at the area of larger molecular weight (lane 2), indicating that PNGase F effectively eliminated partial glycans, i.e., $\mathrm{N}$-glycans; further $\mathrm{O}$-deglycosylation obtained a single brand (lane 5) which migrated to nearly the same distance with $E$. coli-Bgl3A (lane 6). Periodic acid-schiff (PAS) staining was also used to identify glycoprotein (Fig. 1b). Both Bgl3A and $N$-deglycosylated Bgl3A were dyed pinkish red, while $N$ - and $O$-deglycosylated Bgl3A and $E$. coli-Bgl3A were not. It indicated that Bgl3A has both $N$ - and $O$-glycosylations, which are successfully eliminated by PNGase $F$ and $\alpha$-mannosidase sequentially.

The $\mathrm{pH}$ stabilities of deglycosylated enzymes were compared with that of Bgl3A and E. coli-Bgl3A (Fig. 3). The pH stability of $N$-glycosylated Bgl3A had no difference from that of Bgl3A, while $O$ - and $N$-glycosylated Bgl3A exhibited much better $\mathrm{pH}$ tolerance, retaining stable over $\mathrm{pH} 3.0-11.0$. It revealed the influence of $O$-glycosylation on $\mathrm{pH}$ stability of Bgl3A.

\section{The stability and kinetic parameters of $O$-glycosylation sites mutants}

As shown above, $\mathrm{O}$-glycosylation was predicted to mainly occur at residues 417-429 of Bgl3A. In contrast, its close homolog, the GH3 $\beta$-glucosidase NfBGL1 from $N$. fischeri $\mathrm{P} 1$ [48] (73\% identity), is much more $\mathrm{pH}$ tolerant and has less potential $\mathrm{O}$-glycosylation sites at this location. Thus two Bgl3A mutants, designated M1 and M2, with sequence substitution from NfBGL1 and O-glycosylation site substitution by alanine (Fig. 4a, b), were constructed to determine the influence of $O$-glycosylation on $\mathrm{pH}$ stability. Both mutants were expressed in P. pastoris and $E$. coli, respectively. SDS-PAGE analysis (Fig. 4c) indicated that $N$-glycans were effectively eliminated from wild type and mutant proteins by PNGase F. As results, N-deglycosylated Bgl3A appeared as a dispersing band in the gel since it still contained $O$-glycosylation, while two mutants migrated single bands with theoretical molecular masses. Moreover, the enzyme $\mathrm{pH}$ stability at $37{ }^{\circ} \mathrm{C}$ varied a lot when produced in different expression systems (Fig. 5a, b). Mutants M1 and M2 expressed in P. pastoris showed tolerance over a broader $\mathrm{pH}$ range than wild type Bgl3A (Fig. 5a), and had no obvious variation in thermostability (Fig. 5c, d). In contrast, the wild type and mutant enzymes expressed in $E$. coli had no significant difference in $\mathrm{pH}$ stability, retaining stable over a $\mathrm{pH}$ range of 4.0-10.0.

In comparison with wild type Bgl3A, mutants M1 and M2 had no much changes in specific activity, inhibition constant and kinetics, although their catalytic efficiencies towards $p$ NPG were lowered significantly because of increased $K_{\mathrm{m}}$ values (Table 2). Analysis of the secondary structures of all recombinant proteins by CD spectrometry indicated little variance among proteins expressed in the same host (Additional file 2). The results suggested that residue substitution had no effect on the folding structure of Bgl3A, while proteins produced by different hosts had slight difference.

\section{Enzymatic saccharification of cellulose materials}

The commercial cellulase preparation Celluclast $1.5 \mathrm{~L}$ (Novo Nodisk A/S) from the hyperproducing mutant 


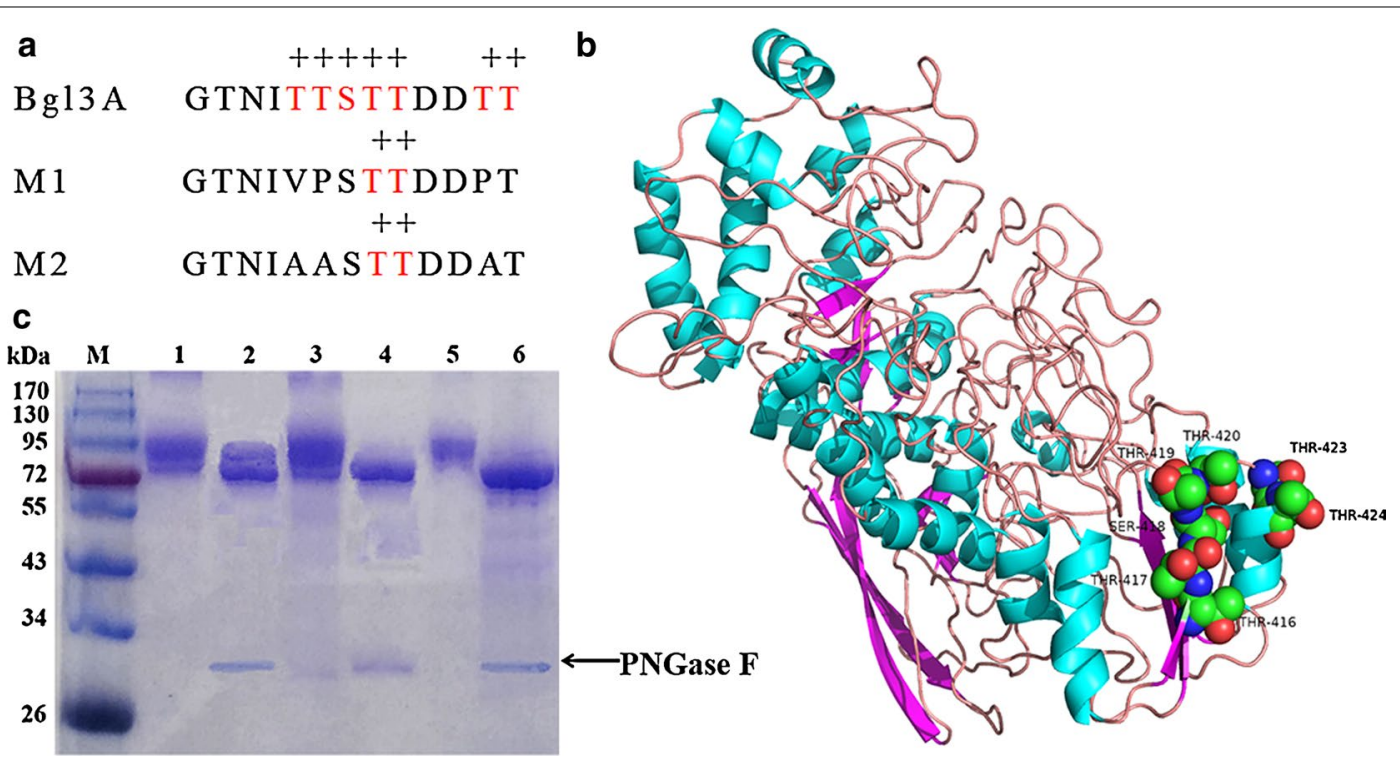

Fig. 4 Sequence, structure and molecular mass analyses of wild type and mutant Bgl3A proteins. a The amino acid sequences of wild type and mutant enzymes with potential O-glycosylation sites (http://www.cbs.dtu.dk/services/NetOGlyc/) indicated. b Modeled Bgl3A with Cel3A of H. jecorina (PDB: $3 Z$ YZ) as the template. The potential glycosylated residues are shown in balls. c SDS-PAGE analysis of the wild type and mutant enzymes produced in P. pastoris and treated with/without PNGase F. Lanes M, the standard protein molecular weight markers; 1 the purified Bgl3A; 2 the $\mathrm{N}$-deglycosylated Bgl3A; 3 the purified M1; 4 the $\mathrm{N}$-deglycosylated $\mathrm{M} 1 ; 5$ the purified M2; 6 the $\mathrm{N}$-deglycosylated M2

strain Trichoderma reesei ATCC 26921, which is most commonly used in biomass degradation, works best at $\mathrm{pH} 5.0$ and $50{ }^{\circ} \mathrm{C}$. So, to verify the application values of wild type Bgl3A and two modified mutants under factual conditions, the stability of enzymes was determined at pH 5.0 and $50{ }^{\circ} \mathrm{C}$ (Fig. 6a). The two mutants kept active up to $72 \mathrm{~h}$, remaining over $70 \%$ relative maximum activity, while wild type Bgl3A had a continuous declination in activity. The preferential order of stability was M1 $>$ M2> wild type Bgl3A.

Application potentials of M1 and wild type Bgl3A in saccharification of cellulosic materials were compared with that of commercial Novozyme 188 (Sigma-Aldrich). As shown in Fig. 6b and c, the saccharification efficiencies of Bgl3A and preferable mutant M1 were compared with commercial Novozyme 188 (Sigma-Aldrich) using corn stover as the cellulosic materials. In the blank control group, the commercial T. reesei cellulase Celluclast 1.5L (5 FPU (filter paper activity)/g dry material) released $14.78 \mathrm{mM}$ of reducing sugars from corn stover over $72 \mathrm{~h}$ incubation at $\mathrm{pH} 5.0$ and $50{ }^{\circ} \mathrm{C}$, in which glucose accounted for 4.79 (32.4\%). When added $\beta$-glucosidase at the dosage of $10 \mathrm{BGU}$ ( $\beta$-glucosidase activity)/g dry material, wild type Bgl3A, mutant M1 and commercial Novozyme 188 showed different synergistic actions to promote the saccharification. By releasing $33.83 \mathrm{mM}$ of reducing sugars and $31.35 \mathrm{mM}$ glucose (the glucose conversion rate is $92.7 \%$ ), the synergistic action of Celluclast
1.5L and Novozyme 188 achieved a twofold increase in saccharification efficiency. In contrast, wild type Bgl3A with desirable catalytic properties in combination with Celluclast $1.5 \mathrm{~L}$ only released $19.64 \mathrm{mM}$ of reducing sugars and $17.75 \mathrm{mM}$ of glucose, which are only 58.0 and $56.6 \%$ of that of Celluclast $1.5 \mathrm{~L}$ and Novozyme 188. However, mutant M1 showed improved performance in synergistic enzymatic saccharification. The yields of reducing sugars and fermentable glucose by Celluclast $1.5 \mathrm{~L}$ and mutant $\mathrm{M} 1$ were increased substantially to 30.79 and $28.7 \mathrm{mM}$, respectively, which were both 1.6fold of that of wild type Bgl3A. The glucose conversion rate of mutant M1 was $93.2 \%$, which was higher than that of Novozyme 188.

\section{Discussion}

Thermophilic fungi are well-known to produce abundant plant cell wall-degradating hydrolases with superior characters, such as great catalytic performance, high expression level and excellent stability [16, 20, 21, 24, 49-51]. In decades, studies have been focused on heterologous expression of fungal $\beta$-glucosidases in $P$. pastoris [52-55] and engineering of $\beta$-glucosidases for property improvement $[31,56,57]$. In this study, a novel GH3 $\beta$-glucosidase, Bgl3A, was identified from thermophilic T. leycettanus JCM12802, and expressed in P. pastoris GS115 at high level. The determinations on enzymatic characteristics showed that Bgl3A was a 

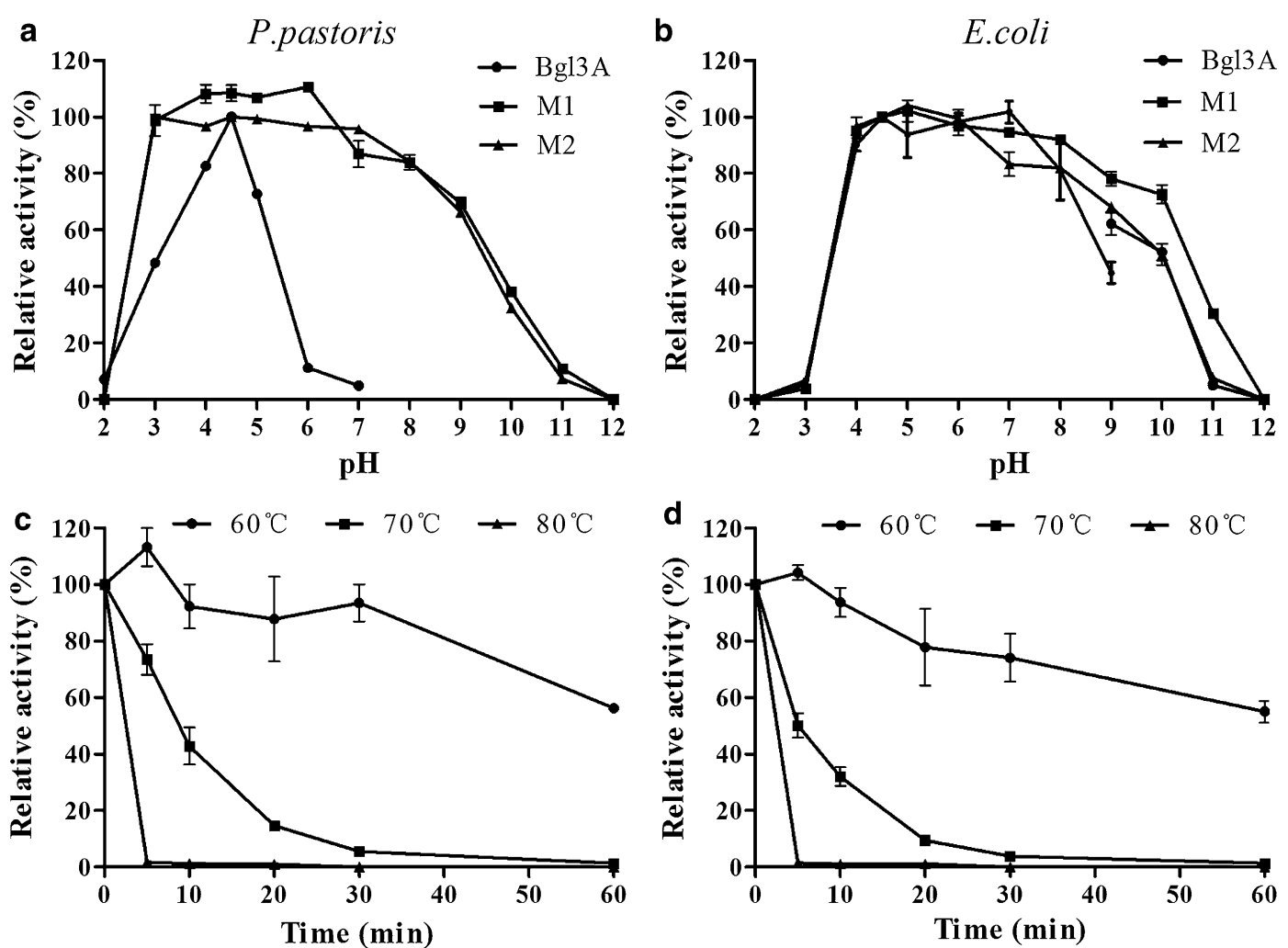

Fig. 5 pH stabilities of wild type and mutant Bgl3A at the same amounts. a Enzymes expressed in P. pastoris GS115; b Enzymes expressed in E. coli BL21; c Thermostability of mutant M1 at 60,70 , and $80^{\circ} \mathrm{C}$ up to $60 \mathrm{~min}$; d Thermostability of mutant $\mathrm{M} 2$ at 60,70 , and $80^{\circ} \mathrm{C}$ up to 60 min
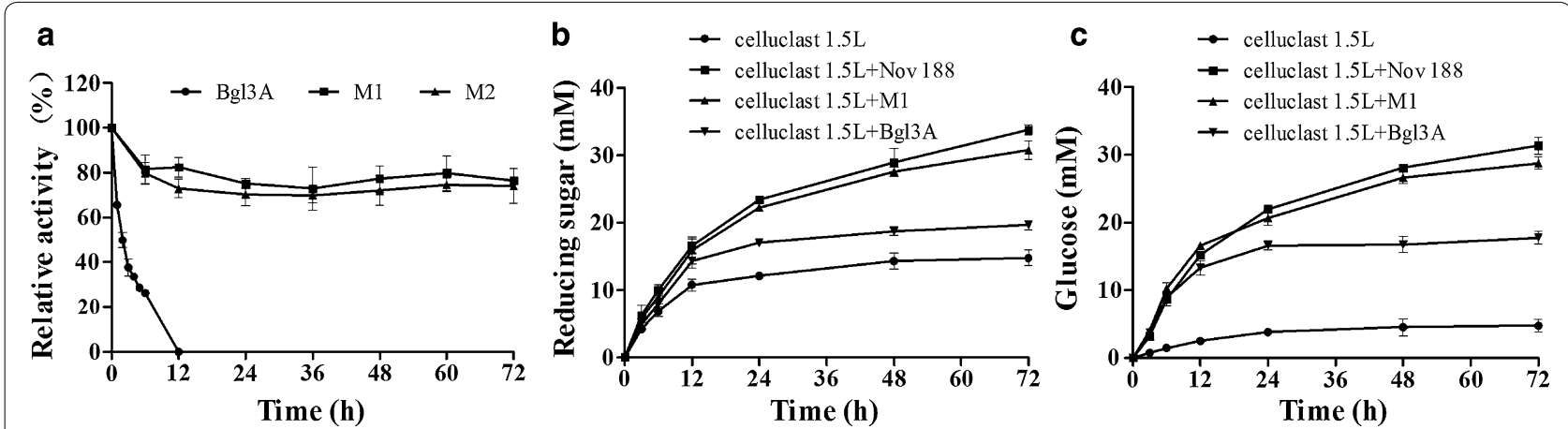

Fig. 6 Enzyme stability and saccharification efficiency of wild type and mutant Bgl3A (10 U/g dry material) in combination with commercial cellulase ( $5 \mathrm{U} / \mathrm{g}$ dry material). The pretreated corn stover was used as the substrate. a Enzyme stability under $\mathrm{pH} 5.0$ and $50^{\circ} \mathrm{C} ; \mathbf{b}$ The reducing sugar released by enzyme(s); c The glucose released by enzyme(s)

thermophilic and acidic $\beta$-glucosidase with good thermostability and high-level production. The optimal temperature $\left(75^{\circ} \mathrm{C}\right)$ of $\mathrm{Bgl} 3 \mathrm{~A}$ was higher than that of most fungal $\beta$-glucosidases $\left(45-65^{\circ} \mathrm{C}\right)[51,55,58-60]$ including the most widely used commercial Novozyme 188 [21]. And its high specific activity and catalytic efficiency towards $p$ NPG and cellobiose are much greater than most $\beta$-glucosidases $[51,54,60]$. These advantages make
Bgl3A one of the most qualified candidates for industrial applications.

Moreover, the application bottleneck of Bgl3A, i.e., the narrow $\mathrm{pH}$ stability range (only $\mathrm{pH} 4.0-5.0$ when expressed in $P$. pastoris), has been overcome by sitedirected mutagenesis. Enzyme adaptation and tolerance to changeable conditions is one of the most important properties for industrial applications. There was no 
doubt that the defect in $\mathrm{pH}$ stability would limit the performance of the enzyme in practical uses. So it was of great importance to find out the reason that caused the instability and even to improve the enzyme by molecular modification. Glycosylation is known to be the main PTM of secretory proteins in P. pastoris. As previously mentioned, glycosylation has diverse effects on enzyme properties. Sometimes the effect is unexpected and unfavorable. In the case of Bgl3A that contains three potential $\mathrm{N}$-glycosylation sites (Asn23, Asn207 and Asn278) and nine $O$-glycosylation sites (residues $313,417-421$, 424,425 and 429), the enzyme was heavily glycosylated when expressed in P. pastoris, and was liable at pHs lower than 4.0 or higher than 5.0. However, when expressed in E. coli, E. coli-Bgl3A without any glycosylation was stable over a broad range of $\mathrm{pH} 4.0-10.0$. It could be inferred that the variance of PTMs probably changed the recombinant proteins. Through the sequential enzymatic deglycosylation of $\mathrm{N}$-linked and $\mathrm{O}$-linked glycans, we found that it is $O$-glycosylation that accounts for the $\mathrm{pH}$ liability of Bgl3A. By removing two potential $O$-glycosylation sites, both mutants $\mathrm{M} 1$ and $\mathrm{M} 2$ gained $\mathrm{pH}$ tolerance over a much broader $\mathrm{pH}$ range (3.0-10.0) without unfavorable side-effects on other enzymatic and catalytic properties. Moreover, it was also found that $O$-deglycosylation by $\alpha$-mannosidase and removal of $O$-glycosylation sites by site-directed mutagenesis both improved the enzyme $\mathrm{pH}$ stability at similar levels, while had no effect on mutant thermostability. The results confirmed that $O$-glycosylation is the main reason accounting for the narrowed $\mathrm{pH}$ stability range. As a whole, we concluded that excessive $O$-glycosylation could negatively affect the $\mathrm{pH}$ stability of $\beta$-glucosidase Bgl3A, and reducing the degree of $O$-glycosylation could dramatically improve the $\mathrm{pH}$ tolerance of the enzyme. Considering the far distance of $O$-glycosylation sites from the catalytic pocket of Bgl3A, $\mathrm{O}$-glycans may influence Bgl3A stability by changing the enzyme spatial structure.

As known, the conversion of polysaccharides to glucose during saccharification process is regarded as both the rate and cost limiting steps in the production of biofuels efficient utilization of cellulose biomass. Therefore, the performance of a $\beta$-glucosidase in the process of synergetic enzymatic saccharification is undoubtedly a symbolic index to estimate its application value. With better stability and unchanged activities, mutant M1 released 1.6-folds fermentable sugars compared to wild type Bgl3A, which was approximately equal to that of commercial $\beta$-glucosidase preparation Novozyme 188 with the same activity units in the continuous saccharification process of $72 \mathrm{~h}$ under $\mathrm{pH} 5.0$ and $50{ }^{\circ} \mathrm{C}$. Moreover, mutant M1 had higher catalytic efficiency $(80.5 / \mathrm{s} /$ $\mathrm{mM})$ than commercial Novozyme $188(36 / \mathrm{s} / \mathrm{mM})$ [21] towards natural substrate cellobiose, and produced comparable glucose yield as Novozyme 188. In other words, mutant M1 was more cost-effective since it needed less mass of enzyme protein to reach the required activity. Factually, data also showed that the concentration of glucose released by mutant M1 at the time point of $12 \mathrm{~h}$ was $16.61 \mathrm{mM}$, which was close to the $K_{\mathrm{i}}$ value of $17.0 \mathrm{mM}$. It illustrated that mutant M1 had better performance on cellobiose hydrolyzing at low glucose concentration. And the overtaking of Novozyme 188 during later period might be benefit from its rather high product inhibition constant ( $K_{\mathrm{i}}$ value of $56.0 \mathrm{mM}$ glucose) [22].

\section{Conclusions}

$\beta$-Glucosidase plays a rate-limiting role in biomass conversion. In this study, a thermophilic, acidic, thermostable $\beta$-glucosidase from thermophilic $T$. leycettanus JCM12802 was identified and expressed in $P$. pastoris at high level. To meet the requirements of practical applications, the enzyme was further improved for $\mathrm{pH}$ stability over a broader range. As results, the mutant retained $\mathrm{pH}$ stability over 3.0-11.0 and exhibited comparable performance to commercial enzyme in saccharification of cellulosic materials. This study, not only reveals the negative effect of $O$-glycosylation on $\mathrm{pH}$ stability, but also provides an excellent enzyme candidate for efficient biomass conversion.

\section{Methods}

\section{Strains, media, vectors and chemicals}

The filamentous fungus T. leycettanus JCM12802 was preserved in our laboratory and routinely cultured in the wheat bran medium containing $5 \mathrm{~g} / \mathrm{l} \mathrm{NaCl}, 5 \mathrm{~g} / \mathrm{l}$ $\left(\mathrm{NH}_{4}\right)_{2} \mathrm{SO}_{4}, 1 \mathrm{~g} / \mathrm{KH}_{2} \mathrm{PO}_{4}, 0.5 \mathrm{~g} / \mathrm{l} \mathrm{MgSO} \mathrm{MgH}_{4} \cdot 7 \mathrm{O}, 0.2 \mathrm{~g} / \mathrm{l}$ $\mathrm{CaCl}_{2}, 0.01 \mathrm{~g} / \mathrm{l} \mathrm{FeSO}{ }_{4} \cdot 7 \mathrm{H} 2 \mathrm{O}, 10 \mathrm{~g} / \mathrm{l}$ agar and $24 \mathrm{~g} / \mathrm{l}$ wheat bran at $45{ }^{\circ} \mathrm{C}$ for 6 days. Escherichia coli Trans1-T1 and vector pEASY-T3 (TransGen, Beijing, China) were used for gene cloning. Vectors pET30a $(+)$ and pPIC9 and E. coli BL21(DE3) and P. pastoris GS115 (Invitrogen, Carlsbad, CA) were used for prokaryotic and eukaryotic expression. The DNA purification kit, restriction endonucleases and $L A$ Taq DNA polymerase were purchased from TaKaRa (Otsu, Japan). T4 DNA ligase and the total RNA isolation system kit were purchased from Promega (Madison, WI). The cDNA synthesis kit was purchased from TransGen.

Barley $\beta$-glucan, Avicel, 4-nitrophenyl $\beta$-Dglucopyranoside ( $p \mathrm{NPG}$ ), 4-nitrophenyl $\beta$-D-xylopyranoside ( $p$ NPX), 4-nitrophenyl $\alpha$-L-arabinofuranoside ( $p$ NPAf), 4-nitrophenyl $\alpha$-D-galactopyranoside ( $p \mathrm{NPGal}), 4$-nitrophenyl $\alpha$-L-arabinopyranoside ( $p \mathrm{NPAb}), 4$-nitrophenyl $\beta$-Dcellobioside $(p$ NPC), disaccharides cellobiose, sophorose and gentiobiose, and soybean flavones daidzin, genistin 
and glycitin were purchased from Sigma-Aldrich (St. Louis, $\mathrm{MO})$. Sodium carboxymethylcellulose (CMC-Na), laminarin and lichenin were obtained from Megazyme (Wicklow, Ireland). All other chemicals were of analytical grade and commercially available.

\section{Gene cloning and sequence analysis}

Genomic DNA of strain T. leycettanus JCM12802 was extracted and purified as the template. To obtain the core region of the $\beta$-glucosidase gene (bgl $3 A$ ), a degenerate primer set specific for fungal GH3 $\beta$-glucosidases (DP-F and DP-R, shown in Additional file 3) was designed based on the conserved amino acid sequences SSNIDD and GLDMT(A)MPGD(S). The resulting PCR product was gel purified, ligated with pEasy-T3 cloning vector and then transformed into E. coli Trans1-T1 for sequencing. The flanking regions were obtained by TAIL-PCR [61] using a genome walking kit (TaKaRa) and three pairs of specific nested primers (shown in Additional file 1: Table S1), sequenced, and assembled with the known core sequence to give the full-length $b g l 3 A$.

The total RNA of T. leycettanus JCM12802 was extracted from the mycelia after 4 days' growth in the inducing medium, and was reverse transcribed into cDNA by TransScript ${ }^{\circledR}$ One-Step gDNA Removal and cDNA Synthesis SuperMix kit (TransGen). The cDNA fragment of $b g l 3 A$ without the signal peptide-coding sequence was then amplified with an annealing temperature of $60{ }^{\circ} \mathrm{C}$ and two primer sets (shown in Additional file 1: Table S1) specific for prokaryotic and eukaryotic expression. The PCR products were purified and ligated into the pEASY-T3 vector for sequencing.

Nucleotide and protein sequences were aligned using the BLASTn and BLASTp programs (http://www.ncbi. nlm.nih.gov/BLAST/), respectively. Vector NTI Advance 10.0 software (Invitrogen) was used to analyze the nucleotide sequence and to predict the molecular weight and $p \mathrm{I}$ of deduced proteins. Genes, introns, exons and transcription initiation sites were predicted using the online software FGENESH (http://linux1.softberry.com/berry. phtml). Multiple sequence alignments were performed with the ClustalW software. Putative signal peptide and glycosylation sites were predicted by the SignalP 4.1 server (http://www.cbs.dtu.dk/services/SignalP/) and the NetNGlyc 1.0 Server (http://www.cbs.dtu.dk/services/ NetNGlyc/), respectively.

\section{Enzyme expression and purification in P. pastoris}

The cDNA fragment without the signal peptide-coding sequence and the pPIC9 vector were both digested by EcoRI and NotI and ligated into in-frame fusion of the $\alpha$-factor signal peptide to construct the recombinant plasmids, which were linearized using BglII and transformed into P. pastoris GS115 competent cells by electroporation using a Gene Pulser X cell Electroporation System (Bio-Rad, Hercules, CA). Minimal dextrose medium (MD) plates were used to screen positive transformants. The positive transformants were transferred to buffered glycerol complex medium (BMGY) and grown at $30{ }^{\circ} \mathrm{C}$ for 2 days. The cells were collected by centrifugation and resuspended in buffered methanol complex medium (BMMY) containing $0.5 \%$ methanol for induction. The $\beta$-glucosidase activities of the culture supernatants were assayed using $p$ NPG as the substrate, and the transformants exhibiting the highest $\beta$-glucosidase activities were subjected to high level expression in 1-l Erlenmeyer flasks and 3-1 fermentor according to the Pichia expression manual (Invitrogen).

The culture supernatants aforementioned were collected by centrifugation $\left(12,000 \times g, 4{ }^{\circ} \mathrm{C}\right.$, and $\left.10 \mathrm{~min}\right)$ to remove cell debris and undissolved materials, followed by concentration through a Vivaflow ultrafiltration membrane (Vivascience, Hannover, Germany) with a molecular weight cut-off of $5 \mathrm{kDa}$. The crude enzyme was loaded onto a FPLC HiTrap Q Sepharose XL $5 \mathrm{ml}$ column (GE Healthcare, Uppsala, Sweden) that was equilibrated with $20 \mathrm{mM}$ Tris- $\mathrm{HCl}(\mathrm{pH}$ 8.0). Proteins were eluted using a linear gradient of $\mathrm{NaCl}(0-1.0 \mathrm{M})$ in the buffer mentioned above at a flow rate of $3.0 \mathrm{ml} / \mathrm{min}$. Fractions exhibiting $\beta$-glucosidase activities were pooled and subjected to sodium dodecyl sulfate-polyacrylamide gel electrophoresis (SDS-PAGE). The protein concentration was determined by a Bradford assay with bovine serine albumin as a standard.

\section{Enzyme expression and purification in E. coli}

Both the cDNA fragment without the signal peptidecoding sequence and pET-30a $(+)$ were digested by NdeI and EcoRI and ligated to constructed recombinant plasmids and individually transformed into E. coli BL21 (DE3) competent cells. Positive transformants were verified by DNA sequencing. After induction at $30{ }^{\circ} \mathrm{C}$ for $6 \mathrm{~h}$ by $0.6 \mathrm{mM}$ of isopropyl $\beta$-D-1-thiogalactopyranoside (IPTG), the cells (approximately $5 \mathrm{~g}$ ) were collected by centrifugation at $12,000 \times g, 4{ }^{\circ} \mathrm{C}$ for $5 \mathrm{~min}$ and resuspended in $25 \mathrm{ml}$ of lysis buffer $(20 \mathrm{mM}$ Tris- $\mathrm{HCl}, \mathrm{pH}$ 7.0), followed by sonication with an Ultrasonic Cell Disruptor (Scientz, China) on ice (5 s short bursts at $200 \mathrm{~W}$ followed by an interval of $3 \mathrm{~s}$ cooling for 100 times). Cell debris was removed by centrifugation, and the supernatants were subjected to $\mathrm{Ni}^{2+}$-NTA chromatography with a linear gradient of imidazole $(2-300 \mathrm{mM})$ in $50 \mathrm{mM}$ Tris- $\mathrm{HCl}, 0.5 \mathrm{M} \mathrm{NaCl}, \mathrm{pH}$ 7.6. Fractions exhibiting $\beta$-glucosidase activities were pooled and subjected to SDS-PAGE analysis. Elution peaks of a single band with objective size were recovered and concentrated as 
purified enzyme solution. The protein concentration was determined as described above.

\section{Enzyme activity assay}

The $\beta$-glucosidase activity was assayed using $p$ NPG or cellobiose as the substrate. One unit of $\beta$-glucosidase activity was defined as the amount of enzyme that released $1 \mu \mathrm{mol}$ of products per minute under the assay conditions. For substrate $p \mathrm{NPG}$, the standard reaction system consisted of $250 \mu \mathrm{l}$ of appropriately diluted enzyme and $250 \mu \mathrm{l}$ of Mcllvaine buffer containing $2 \mathrm{mM} p$ NPG. After incubation at a certain temperature for $10 \mathrm{~min}, 1.5 \mathrm{ml}$ of $1.0 \mathrm{M} \mathrm{Na}_{2} \mathrm{CO}_{3}$ was added into the system to terminate the reaction. The amount of $p$-nitrophenol $(p \mathrm{NP})$ released was determined spectrophotometrically by reading the absorbance at $405 \mathrm{~nm}$. Each experiment was performed in triplicate. And for cellobiose, the standard reaction was carried out with $70 \mu \mathrm{l}$ of appropriately diluted enzyme and $70 \mu \mathrm{l}$ of McIlvaine buffer containing $2 \mathrm{mM}$ cellobiose for $10 \mathrm{~min}$ followed by a boiling water bath to terminate the reaction. GOD-POD coloring solution $(2.1 \mathrm{ml})$ was then added into the system, and the absorbance at $520 \mathrm{~nm}$ was determined to calculate the amount of released glucose.

\section{Biochemical characterization}

$p$ NPG was used as the substrate for activity assays to investigate the biochemical properties of Bgl3A. The optimal $\mathrm{pH}$ for the $\beta$-glucosidase activity of purified recombinant $\mathrm{Bgl} 3 \mathrm{~A}$ was determined at $75{ }^{\circ} \mathrm{C}$ for $10 \mathrm{~min}$ over a $\mathrm{pH}$ range of 2.0-11.0. Buffers used for the assays were as follows: $100 \mathrm{mM} \mathrm{Na} \mathrm{HPO}_{4}$-citric acid $(\mathrm{pH}$ 2.0-8.0), $100 \mathrm{mM}$ Tris- $\mathrm{HCl}$ (pH 8.0-9.0), and $100 \mathrm{mM}$ glycine- $\mathrm{NaOH}$ (pH 9.0-11.0). To estimate $\mathrm{pH}$ stability, the enzyme was pre-incubated in the buffers mentioned above without substrate at $37^{\circ} \mathrm{C}$ for $1 \mathrm{~h}$, and the residual activities were measured under the standard conditions (pH $4.5,75^{\circ} \mathrm{C}$, and $10 \mathrm{~min}$ ).

The optimal temperature was examined at the $\mathrm{pH}$ optimum by measuring the enzyme activity over the temperature range of 30 and $90{ }^{\circ} \mathrm{C}(\mathrm{pH} 4.5$ and $10 \mathrm{~min})$. The thermostability was investigated by determining the residual enzyme activities under standard conditions $\left(\mathrm{pH} 4.5,75^{\circ} \mathrm{C}\right.$, and $10 \mathrm{~min}$ ) after preincubation at 60,70 and $80^{\circ} \mathrm{C}$ and optimal $\mathrm{pH}$ without substrate for various periods (10-60 min).

The $\beta$-glucosidase activity of purified recombinant Bgl3A was also measured in the presence of $5 \mathrm{mM}$ of various metal ions and chemical reagents $\left(\mathrm{Ag}^{+}, \mathrm{Ca}^{2+}, \mathrm{Li}^{+}, \mathrm{Co}^{2+}\right.$, $\mathrm{Cr}^{3+}, \mathrm{Ni}^{2+}, \mathrm{Cu}^{2+}, \mathrm{Mg}^{2+}, \mathrm{Fe}^{3+}, \mathrm{Mn}^{2+}, \mathrm{Hg}^{2+}, \mathrm{Pb}^{2+}, \mathrm{EDTA}$, SDS or $\beta$-mercaptoethanol) to estimate their effects. The reaction without any additive was used as a blank control.

\section{Substrate specificity and kinetic parameters}

To investigate the substrate specificity of purified recombinant Bgl3A, $1 \%(\mathrm{w} / \mathrm{v})$ of polysaccharides (barley $\beta$-glucan, CMC-Na, Avicel, laminarin, lichenin), disaccharides (cellobiose, sophorose, and gentiobiose), soybean flavones (daidzin, genistin, and glycitin) or $1 \mathrm{mM}$ of $p$-nitrophenyl derivatives ( $p$ NPG, $p$ NPAf, $p$ NPX, $p$ NPGal, $p$ NPAb, $p$ NPC) were used as the substrate to determine their corresponding activities.

The $K_{\mathrm{m}}, V_{\max }$ and $k_{\text {cat }}$ values of purified recombinant Bgl3A were determined under optimal conditions for $5 \mathrm{~min}$ in $100 \mathrm{mM} \mathrm{Na} \mathrm{HPO}_{4}$-citric acid containing 1-10 mM $p$ NPG or cellobiose as the substrate. The data were plotted according to the Lineweaver-Burk method.

\section{Deglycosylation of recombinant Bgl3A produced in $P$. pastoris}

To remove $\mathrm{N}$-glycans attached during heterologous expression in P. pastoris, $5 \mathrm{ml}$ of purified recombinant Bgl3A was incubated with $5000 \mathrm{U}(10 \mu \mathrm{l})$ of peptide$N$-glycosidase F (PNGase F, P0704S, New England Biolabs, Ipswich, MA) at $37{ }^{\circ} \mathrm{C}$ for $12 \mathrm{~h}$ according to the manufacturer's instructions. To remove $O$-glycans, $4 \mathrm{ml}$ of PNGase F-treated Bgl3A was incubated with $10 \mu \mathrm{l}$ of $\alpha$-mannosidase (M7257, Sigma-Aldrich) for $24 \mathrm{~h}$, followed by purification through anion exchange chromatography. Both $\mathrm{N}$ - and $\mathrm{N}$-/O-deglycosylated enzyme samples were analyzed by SDS-PAGE.

\section{Mutant construction and $C D$ analysis}

Based on sequence alignment with the close homolog NfBGL1 from $N$. fischeri P1 [43] (73\% identity), a region (residues 417-429) with several potential $O$-glycosylation sites was identified. By replacing the potential $O$-glycosylation sites with corresponding residues of NfBGL1 or alanine with specific primers M1-F/R and M2-F/R (shown in Additional file 1: Table S1), two mutants, i.e., $\mathrm{M} 1$ and M2, were constructed to enhance the $\mathrm{pH}$ stability of Bgl3A. Enzyme expression and purification of the mutants were conducted as described above.

Far-UV circular dichroism (CD) spectroscopy was used to determine the secondary structures of Bgl3A and its mutants. The spectra between 200 and $260 \mathrm{~nm}$ were collected at a protein concentration of $1 \mathrm{mg} / \mathrm{ml}$ in $\mathrm{PBS}$

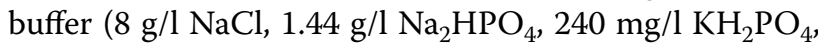
$200 \mathrm{mg} / \mathrm{l} \mathrm{KCl}, \mathrm{pH} 7.2)$ at $25{ }^{\circ} \mathrm{C}$ using a MOS-450 CD spectrometer (Bio-Logic, France), which was equipped with a 1-mm path length quartz cuvette and a temperature control device. Each spectrum was an average of three consecutive scans and was corrected by subtracting the buffer spectrum. 


\section{Enzymatic saccharification}

Corn stover was pretreated by $1 \% \mathrm{NaOH}$ at $121{ }^{\circ} \mathrm{C}$ for $30 \mathrm{~min}$ in an autoclaver, washed with $\mathrm{ddH}_{2} \mathrm{O}$, ovendried, and mixed with $20 \mathrm{ml}$ of $100 \mathrm{mM} \mathrm{Na}_{2} \mathrm{HPO}_{4}$-citric acid buffer ( $\mathrm{pH}$ 5.0) in $50 \mathrm{ml}$ shake flasks at the concentration of $2 \%$ (dry material). The enzyme(s), i.e., Celluclast 1.5L (Cellulase from Trichoderma reesei ATCC 26921, C2730, Sigma-Aldrich) alone (5 FPU/g dry matter) or supplemented with identical units of purified wild type Bgl3A, mutant M1 or commercial liquid Novozyme 188 (Cellobiase from Aspergillus niger, C6105, SigmaAldrich) (10 BGU/g dry material), respectively, were added into the cellulosic preparations and incubated at $50{ }^{\circ} \mathrm{C}$ with an agitation rate of $200 \mathrm{rpm}$ for $96 \mathrm{~h}$. Hydrolyzates were collected at several intervals and centrifuged at $12,000 \mathrm{rpm}, 4{ }^{\circ} \mathrm{C}$ for $10 \mathrm{~min}$. The amounts of reducing sugars and glucose released in the supernatants were determined using the DNS [62] and GOD-POD methods, respectively. All these experiments were conducted with three replicates.

\section{Nucleotide sequence accession number}

The cDNA sequence of $b g l 3 A$ has been submitted to GenBank under the accession number of KU363626.

\section{Additional files}

Additional file 1. Effect of metal ions and chemical reagents on the activity of purified recombinant $\beta$-glucosidase Bgl3A.

Additional file 2. Circular dichroism spectrums of the wild type and mutant proteins of Bgl3A $(0.5 \mathrm{mg} / \mathrm{ml})$.

Additional file 3. Primers used in this study.

\section{Abbreviations}

EG: endo- $\beta$-glucanase; $\mathrm{CBH}$ : cellobiohydrolase; $\mathrm{GH}$ : glycosyl hydrolase; PDB: protein data base; $K_{m}$ : Michaelis constant; $V_{\text {max }}$ : maximum reaction rate; $k_{\text {cat }}$ : turnover number; $p N P$ : 4-nitrophenyl; TAIL-PCR: thermal asymmetric interlaced-PCR; SDS-PAGE: sodium dodecyl sulfate-polyacrylamide gel electrophoresis; DNS: 3,5-dinitrosalicylic acid; GOD-POD: glucose oxidase and peroxidase; CD: circular dichroism.

\section{Authors' contributions}

$W X$ and $X X$ performed the gene cloning, enzyme production and characterization, data processing and drafted the manuscript. LQ and YB predicted the modification sites and performed the homology modeling. HL and RM performed the enzyme purification, participated in the discussion and revised the manuscript. PS and BY were the corresponding authors; they conceived of the study and participated in its design. All authors read and approved the final manuscript.

\footnotetext{
Author details

${ }^{1}$ Key Laboratory for Feed Biotechnology of the Ministry of Agriculture, Feed Research Institute, Chinese Academy of Agricultural Sciences, No. 12 Zhongguancun South Street, Beijing 100081, People's Republic of China. ${ }^{2}$ College of Animal Science, Zhejiang University, Hangzhou 310058, People's Republic of China. ${ }^{3}$ Biotechnology Research Institute, Chinese Academy of Agricultural Sciences, Beijing 100081, People's Republic of China.
}

\section{Acknowledgements}

Not applicable.

\section{Competing interests}

The authors declare that they have no competing interests.

\section{Consent for publication}

All authors consent the manuscript for publication in Biotechnology for Biofuels.

\section{Funding}

This research was supported by the National High Technology Research and Development Program of China (863 Program, 2013AA102803), the National Science Fund for Distinguished Young Scholars (no. 31225026) and the National Natural Science Foundation of China (no. 31372345).

Received: 18 March 2016 Accepted: 11 July 2016

Published online: 20 July 2016

\section{References}

1. Tuck CO, Pérez E, Horváth IT, Sheldon RA, Poliakoff M. Valorization of biomass: deriving more value from waste. Science. 2012;337:695-9.

2. Bornscheuer U, Buchholz K, Seibel J. Enzymatic degradation of (ligno) cellulose. Angew Chem Int Ed Engl. 2014;53:10876-93.

3. Zhang YH, Lynd LR. Toward an aggregated understanding of enzymatic hydrolysis of cellulose: noncomplexed cellulase systems. Biotechnol Bioeng. 2004:88:797-824.

4. Lynd LR, Cushman JH, Wyman CE. Fuel ethanol from cellulosic biomass. Science. 1991;251:1318-23.

5. Lynd LR, Weimer PJ, van ZyI WH, Pretorius IS. Microbial cellulose utilization: fundamentals and biotechnology. Microbiol Mol Biol Rev. 2002:66:506-77.

6. Abdel-Halim ES, Alanazi HH, Al-Deyab SS. Utilization of olive tree branch cellulose in synthesis of hydroxypropyl carboxymethyl cellulose. Carbohydr Polym. 2015;127:124-34.

7. Govumoni SP, Koti S, Kothagouni SY, Venkateshwar S, Linga VR. Evaluation of pretreatment methods for enzymatic saccharification of wheat straw for bioethanol production. Carbohydr Polym. 2013;91:646-50.

8. Singhania RR, Patel AK, Sukumaran RK, Larroche C, Pandey A. Role and significance of $\beta$-glucosidases in the hydrolysis of cellulose for bioethanol production. Bioresour Technol. 2013;127:500-7.

9. Bennati-Granier C, Garajova S, Champion C, Grisel S, Haon M, Zhou S, Fanuel M, Ropartz D, Rogniaux H, Gimbert I, Record E, Berrin JG. Substrate specificity and regioselectivity of fungal AA9 lytic polysaccharide monooxygenases secreted by Podospora anserina. Biotechnol Biofuels. 2015;8:90.

10. Hemsworth GR, Henrissat B, Davies GJ, Walton PH. Discovery and characterization of a new family of lytic polysaccharide monooxygenases. Nat Chem Biol. 2014;10(2):122-6.

11. Busk PK, Lange L. Classification of fungal and bacterial lytic polysaccharide monooxygenases. BMC Genom. 2015;16:368.

12. Wang M, Li Z, Fang X, Wang L, Qu Y. Cellulolytic enzyme production and enzymatic hydrolysis for second-generation bioethanol production. Adv Biochem Eng Biotechnol. 2012;128:1-24.

13. Hasunuma T, Okazaki F, Okai N, Hara KY, Ishii J, Kondo A. A review of enzymes and microbes for lignocellulosic biorefinery and the possibility of their application to consolidated bioprocessing technology. Bioresour Technol. 2013;135:513-22.

14. Wilson DB. Cellulases and biofuels. Curr Opin Biotechnol. 2009;20:295-9.

15. Phitsuwan P, Laohakunjit N, Kerdchoechuen O, Kyu KL, Ratanakhanokchai K. Present and potential applications of cellulases in agriculture, biotechnology, and bioenergy. Folia Microbiol (Praha). 2013;58:163-76.

16. Haven $\mathrm{MO}$, Jørgensen $\mathrm{H}$. Adsorption of $\beta$-glucosidases in two commercial preparations onto pretreated biomass and lignin. Biotechnol Biofuels. 2013:6:165.

17. Rodrigues AC, Haven M $\varnothing$, Lindedam J, Felby C, Gama M. Celluclast and Cellic ${ }^{\circledR}$ CTec2: saccharification/fermentation of wheat straw, solid-liquid partition and potential of enzyme recycling by alkaline washing. Enzyme Microb Technol. 2015:79-80:70-7.

18. Borin GP, Sanchez CC, de Souza AP, de Santana ES, de Souza AT, Leme APF, Squina FM, Buckeridge M, Goldman GH, Oliveira JV. Comparative 
secretome analysis of Trichoderma reesei and Aspergillus niger during growth on sugarcane biomass. PLoS One. 2015;10:e0129275.

19. Kumar MR, Kumaran MD, Balashanmugam P. Production of cellulase enzyme by Trichoderma reesei Cefl9 and its application in the production of bio-ethanol. Pak J Biol Sci. 2014;17:735-9.

20. Baba Y, Sumitani II, Tani S, Kawaguchi T. Characterization of Aspergillus aculeatus $\beta$-glucosidase 1 accelerating cellulose hydrolysis with Trichoderma cellulase system. AMB Express. 2015;5:3.

21. Chauve M, Mathis H, Huc D, Casanave D, Monot F, Ferreira NL. Comparative kinetic analysis of two fungal $\beta$-glucosidases. Biotechnol Biofuels. 2010;3:3.

22. Teugjas H, Väljamäe P. Selecting $\beta$-glucosidases to support cellulases in cellulose saccharification. Biotechnol Biofuels. 2013:6:105.

23. Ng IS, Tsai SW, Ju YM, Yu SM, Ho TH. Dynamic synergistic effect on Trichoderma reesei cellulases by novel $\beta$-glucosidases from Taiwanese fungi. Bioresour Technol. 2011;102:6073-81.

24. Prawitwong P, Waeonukul R, Tachaapaikoon C, Pason P, Ratanakhanokchai K, Deng L, Sermsathanaswadi J, Septiningrum K, Mori Y, Kosugi A. Direct glucose production from lignocellulose using Clostridium thermocellum cultures supplemented with a thermostable $\beta$-glucosidase. Biotechnol Biofuels. 2013;6:184.

25. Nestl BM, Nebel BA, Hauer B. Recent progress in industrial biocatalysis. Curr Opin Chem Biol. 2011;15:187-93.

26. Mallek-Fakhfakh H, Belghith $\mathrm{H}$. Physicochemical properties of thermotolerant extracellular $\beta$-glucosidase from Talaromyces thermophilus and enzymatic synthesis of cello-oligosaccharides. Carbohydr Res. 2016:419:41-50

27. Pei XQ, Yi ZL, Tang CG, Wu ZL. Three amino acid changes contribute markedly to the thermostability of $\beta$-glucosidase BglC from Thermobifida fusca. Bioresour Technol. 2011;102:3337-42.

28. Liu W, Hong J, Bevan DR, Zhang YH. Fast identification of thermostable beta-glucosidase mutants on cellobiose by a novel combinatorial selection/screening approach. Biotechnol Bioeng. 2009:103:1087-94.

29. Haitjema CH, Solomon KV, Henske JK, Theodorou MK, O'Malley MA. Anaerobic gut fungi: advances in isolation, culture, and celluloIytic enzyme discovery for biofuel production. Biotechnol Bioeng. 2014;111:1471-82.

30. Paye JM, Guseva A, Hammer SK, Gjersing E, Davis MF, Davison BH, Olstad J, Donohoe BS, Nguyen TY, Wyman CE, Pattathil S, Hahn MG, Lynd LR. Biological lignocellulose solubilization: comparative evaluation of biocatalysts and enhancement via cotreatment. Biotechnol Biofuels. 2016:9:8.

31. Decker CH, Visser J, Schreier P. $\beta$-Glucosidases from five black Aspergillus species: study of their physico-chemical and biocatalytic properties. J Agric Food Chem. 2000;48:4929-36.

32. Korotkova OG, Semenova MV, Morozova WV, Zorov IN, Sokolova LM, Bubnova TM, Okunev ON, Sinitsyn AP. Isolation and properties of fungal B-glucosidases. Biochem Mosc. 2009;74:569-77.

33. Jung SK, Parisutham V, Jeong SH, Lee SK. Heterologous expression of plant cell wall degrading enzymes for effective production of cellulosic biofuels. J Biomed Biotechnol. 2012;2012:405842.

34. Voet D, Voet JG, Pratt CW. Fundamentals of biochemistry: life at the molecular level. Hoboken: Wiley; 2006.

35. Imberty A, Pérez S. Stereochemistry of the $\mathrm{N}$-glycosylation sites in glycoproteins. Protein Eng. 1995:8:699-709.

36. Imperiali B, Rickert KW. Conformational implications of asparagine-linked glycosylation. Proc Natl Acad Sci USA. 1995;92:97-101.

37. Rodriguez E, Wood ZA, Karplus PA, Lei XG. Site-directed mutagenesis improves catalytic efficiency and thermostability of Escherichia coli pH 2.5 acid phosphatase/phytase expressed in Pichia pastoris. Arch Biochem Biophys. 2000;382:105-12.

38. Spiro RG. Protein glycosylation: nature, distribution, enzymatic formation, and disease implications of glycopeptide bonds. Glycobiology. 2002;12:43R-56R.

39. Dai M, Yu C, Fang T, Fu L, Wang J, Zhang J, Ren J, Xu J, Zhang X, Chen W. Identification and functional characterization of glycosylation of recombinant human platelet-derived growth factor-BB in Pichia pastoris. PLoS One. 2015;10:e0145419.

40. Daly R, Hearn MT. Expression of heterologous proteins in Pichia pastoris: a useful experimental tool in protein engineering and production. J Mol Recognit. 2005;18:119-38.
41. Sudbery PE. The expression of recombinant proteins in yeasts. Curr Opin Biotechnol. 1996;7:517-24.

42. Hamilton SR, Gerngross TU. Glycosylation engineering in yeast: the advent of fully humanized yeast. Curr Opin Biotechnol. 2007;18:387-92.

43. Rana NA, Haltiwanger RS. Fringe benefits: functional and structural impacts of O-glycosylation on the extracellular domain of Notch receptors. Curr Opin Struct Biol. 2011;21:583-9.

44. Halim A, Larsen IS, Neubert P, Joshi HJ, Petersen BL, Vakhrushev SY, Strahl $\mathrm{S}$, Clausen $\mathrm{H}$. Discovery of a nucleocytoplasmic O-mannose glycoproteome in yeast. Proc Natl Acad Sci USA. 2015;112:15648-53.

45. Karkehabadi S, Helmich KE, Kaper T, Hansson H, Mikkelsen NE, Gudmundsson M, Piens K, Fujdala M, Banerjee G, Scott-Craig JS, Walton JD, Phillips GN Jr, Sandgren M. Biochemical characterization and crystal structures of a fungal family $3 \beta$-glucosidase, Cel3A from Hypocrea jecorina. J Biol Chem. 2014;289:31624-37.

46. Feng $T$, Liu $H, X u Q$, Sun J, Shi H. Identification and characterization of two endogenous $\beta$-glucosidases from the termite Coptotermes formosanus. Appl Biochem Biotechnol. 2015;176(7):2039-52.

47. Xie J, Zhao D, Zhao L, Pei J, Xiao W, Ding G, Wang Z. Overexpression and characterization of a $\mathrm{Ca}^{2+}$ activated thermostable $\beta$-glucosidase with high ginsenoside Rb1 to ginsenoside 20(S)-Rg3 bioconversion productivity. J Ind Microbiol Biotechnol. 2015;42:839-50.

48. Yang X, Ma R, Shi P, Huang H, Bai Y, Wang Y, Yang P, Fan Y, Yao B. Molecular characterization of a highly-active thermophilic $\beta$-glucosidase from Neosartorya fischeri P1 and its application in the hydrolysis of soybean isoflavone glycosides. PLoS One. 2014;9:e106785.

49. Chen HL, Chen YC, Lu MY, Chang JJ, Wang HT, Ke HM, Wang TY, Ruan SK, Wang TY, Hung KY, Cho HY, Lin WT, Shih MC, Li WH. A highly efficient $\beta$-glucosidase from the buffalo rumen fungus Neocallimastix patriciarum W5. Biotechnol Biofuels. 2012;5:24.

50. Zhang Z, Liu J, Lan J, Duan C, Ma Q, Feng J. Predominance of Trichoderma and Penicillium in cellulolytic aerobic filamentous fungi from subtropical and tropical forests in China, and their use in finding highly efficient B-glucosidase. Biotechnol Biofuels. 2014;7:107.

51. Pei J, Pang Q, Zhao L, Fan S, Shi H. Thermoanaerobacterium thermosaccharolyticum $\beta$-glucosidase: a glucose-tolerant enzyme with high specific activity for cellobiose. Biotechnol Biofuels. 2012;5:31.

52. Tang Z, Liu S, Jing H, Sun R, Liu M, Chen H, Wu Q, Han X. Cloning and expression of $A$. oryzae $\beta$-glucosidase in Pichia pastoris. Mol Biol Rep. 2014:41:7567-73.

53. Batra J, Beri D, Mishra S. Response surface methodology based optimization of $\beta$-glucosidase production from Pichia pastoris. Appl Biochem Biotechnol. 2014;172:380-93.

54. Pei X, Zhao J, Cai P, Sun W, Ren J, Wu Q, Zhang S, Tian C. Heterologous expression of a GH3 $\beta$-glucosidase from Neurospora crassa in Pichia pastoris with high purity and its application in the hydrolysis of soybean isoflavone glycosides. Protein Expr Purif. 2015;119:75-84.

55. Cao LC, Wang ZJ, Ren GH, Kong W, Li L, Xie W, Liu YH. Engineering a novel glucose-tolerant $\beta$-glucosidase as supplementation to enhance the hydrolysis of sugarcane bagasse at high glucose concentration. Biotechnol Biofuels. 2015;8:202.

56. Hassan N, Geiger B, Gandini R, Patel BK, Kittl R, Haltrich D, Nguyen TH, Divne C, Tan TC. Engineering a thermostable Halothermothrix orenii $\beta$-glucosidase for improved galacto-oligosaccharide synthesis. Appl Microbiol Biotechnol. 2016;100:3533-43.

57. Sun $H, X u e Y$, Lin Y. Enhanced catalytic efficiency in quercetin-4'glucoside hydrolysis of Thermotoga maritima $\beta$-glucosidase A by sitedirected mutagenesis. J Agric Food Chem. 2014;62:6763-70.

58. Langston J, Sheehy N, Xu F. Substrate specificity of Aspergillus oryzae family $3 \beta$-glucosidase. Biochim Biophys Acta. 2006;1764:972-8.

59. Yoon JJ, Kim KY, Cha CJ. Purification and characterization of thermostable $\beta$-glucosidase from the brown-rot basidiomycete Fomitopsis palustris grown on microcrystalline cellulose. J Microbiol. 2008;46:51-5.

60. Karnaouri A, Topakas E, Paschos T, Taouki I, Christakopoulos P. Cloning, expression and characterization of an ethanol tolerant GH3 $\beta$-glucosidase from Myceliophthora thermophila. Peer J. 2013;1:e46.

61. Liu YG, Whittier RF. Thermal asymmetric interlaced PCR: automatable amplification and sequencing of insert end fragments from P1 and YAC clones for chromosome walking. Genomics. 1995;25:674-81.

62. Miller GL. Use of dinitrosalicylic acid reagent for determination of reducing sugar. Anal Chem. 1959;31:426-8. 